\title{
Axillary metastasis as the first manifestation of male breast cancer:
}

\section{a case report}

\author{
Guo-Li Gu*1, Shi-Lin Wang ${ }^{1}$, Xue-Ming Wei ${ }^{1}$, Li Ren ${ }^{2}$ and Fu-Xian Zou ${ }^{3}$
}

Address: ${ }^{1}$ Department of General Surgery, the General Hospital of Chinese PLA Air force, Beijing City, 100142, PR China, ${ }^{2}$ Department of Pathology, the General Hospital of Chinese PLA Air force, Beijing City, 100142, PR China and ${ }^{3}$ Surgical Department of the Affiliated Hospital, Jiangxi University of Science and Technology, Ganzhou City, Jiangxi Province 341000, PR China

Email: Guo-Li Gu* - kzggl@163.com; Shi-Lin Wang - kzgglggl@yahoo.com; Xue-Ming Wei - kzggl@yahoo.com.cn; Li Ren-kzggl@hotmail.com; Fu-Xian Zou - hero1822@163.com

* Corresponding author

Published: 30 October 2008

Cases Journal 2008, I:285 doi:10.1 186/1757-1626-1-285

This article is available from: http://www.casesjournal.com/content/l/I/285

This is an Open Access article distributed under the terms of the Creative Commons Attribution License (http://creativecommons.org/licenses/by/2.0), which permits unrestricted use, distribution, and reproduction in any medium, provided the original work is properly cited.

\begin{abstract}
Background: Breast cancer is very rare in men, and the occurrence of occult breast cancer which present axillary metastasis as the first manifestation is even rarer in men.

Case presentation: We report a 72-year-old male Han-Chinese patient who presented axillary metastasis as the first manifestation of breast cancer and got correctly diagnoses by histological examination. He underwent modified radical mastectomy and axillary dissection on II Apr 2006. The histopathologic examination showed that no tumor focus was found in his breast tissue, but two out of fifteen of axillary lymph nodes were invaded by infiltrating ductal carcinoma. The IHC stain showed that estrogen receptor (ER) and progestin receptor (PR) were negative, Human epidermal receptor (HER-2) oncoprotein (+++), P53 protein expressed (+++), Bcl-2 oncoprotein $(+++), n m 23$ protein $(++)$, proliferating cell nuclear antigen (PCNA) $(+++)$ and multidrugresistance protein (MRP) (++). After operation, he did not receive endocrine therapy, chemotherapy and radiotherapy because of his senility. He is alive without any residual or metastasis disease 29 months after being diagnosed.
\end{abstract}

Conclusion: This is the first case in our hospital that presents axillary metastases as the first manifestation of male breast cancer.

\section{Background}

Breast cancer is very rare in men, accounting for less than $1 \%$ of all breast cancers and less than $1 \%$ of all cancers in men $[1,2]$; and the occurrence of occult breast cancer is even rarer in men [3]. We report a 72-year-old male HanChinese patient with occult breast cancer who was diagnosed by histological examination and Immunohistochemical (IHC) stain. It is the first male case of our hospital that presents axillary metastasis as the first manifestation of occult breast cancer.

\section{Case presentation}

A 72-year-old male Han-Chinese patient presented with a painless and enlarged lymph node in the right axillary for about 6 months without any palpable breast mass (Figure 1). His history showed that no evidence of liver diseases; no medication had been taken, and in particular, there was no history of hormonal treatment. The axillary lymph node biopsy showed that it was invaded by infiltrating ductal carcinoma (IDC) which was in suspect metastasized from breast. The patient was kept in hospital and 


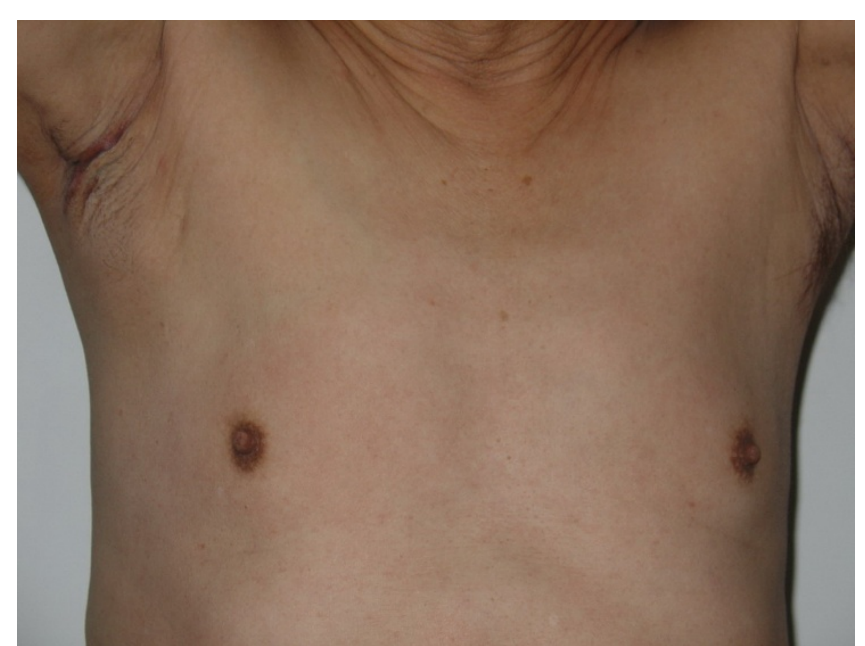

Figure I

External photography of patient's chest. showing enlarged lymph node in the right axillary after biopsy, without palpable breast mass.

took a series of physical, X-ray and ultrasonic examinations. But no other focuses were found in body. The result of the hepatic function test was natural. The biopsy slice was circulated and opinions were sought from fellows of other hospitals. Then, the pathologists came to a conclusion that the male patient was a case with occult breast cancer. The patient underwent a modified radical mastectomy and axillary dissection on 11 April 2006. The histological examination of paraffin sections stained with hematoxylin and eosin (HE) revealed that no tumor focus was found in breast, but two out of fifteen of axillary lymph nodes were invaded by IDC. The histological examination showed the lymph tissue massively and diffusively infiltrated with big and relatively round tumor cells that are tightly cohesive and displayed round-toovoid nuclei and a thin rim of cytoplasm with an occasional intracytoplasmic lumen (Figure 2). The IHC stain (Figure 3, 4, 5, 6, 7, 8) showed estrogen receptor (ER) and progestin receptor (PR) were negative, P53 protein expressed $(+++)$, proliferating cell nuclear antigen (PCNA) $(+++)$, Bcl-2 oncoprotein $(+++)$, nm23 protein $(++)$, multidrug-resistance protein (MRP) $(++)$, Human epidermal receptor (HER-2) oncoprotein $(+++)$. This patient did not receive endocrine therapy, chemotherapy and radiotherapy after operation. He is alive without any residual or metastasis disease 29 months after being diagnosed; and he is still in follow-up.

\section{Discussion}

Breast cancer is very rare in men. Epidemiological studies showed that the rate of male breast cancer is $0.5 \%-1 \%$, in most western countries, and $6 \%$ or more in Tanzania and in Central Africa $[1,2]$. The reasons for this geographic var-

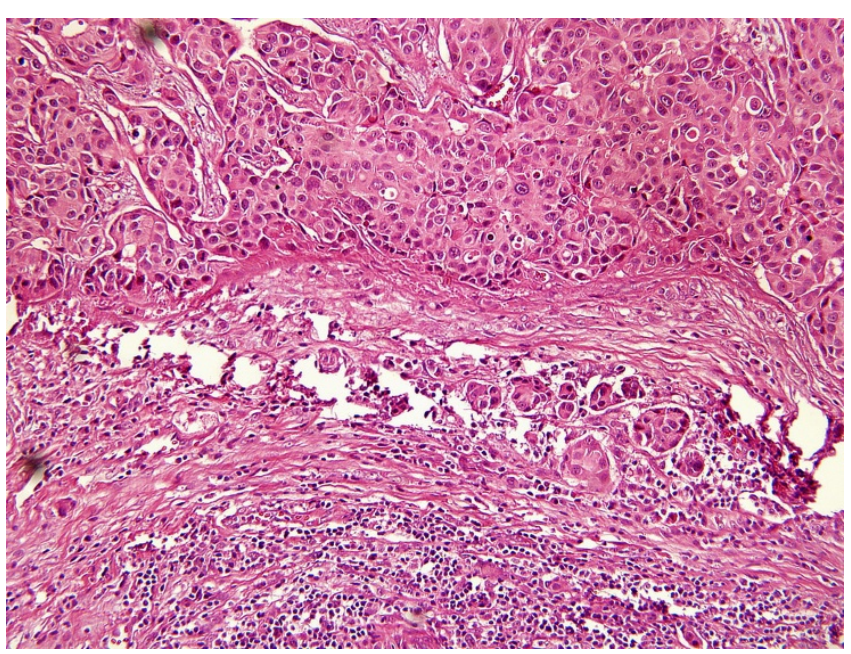

\section{Figure 2}

Metastatic IDC in axillary lymph node. the structure of lymph node which was invaded by metastatic IDC has been destroyed. Big, relatively round tumor cells can be seen invading the lymph node tissue (HE stain, original magnification $\times 200$ ).

iability remain unclear. Recent epidemiologic data suggested that the incidence of male breast cancer has been steadily increasing [4]. However, the pathogenesis of male breast cancer is still unclear. The epidemiologic risk factors may include prostate cancer and its endocrine therapy, gynecomastia, occupational exposures (e.g., electromagnetic fields, polycyclic aromatic hydrocarbons, and high temperatures), dietary factors (e.g., meat intake, fruit and vegetable consumption), and alcohol intake.

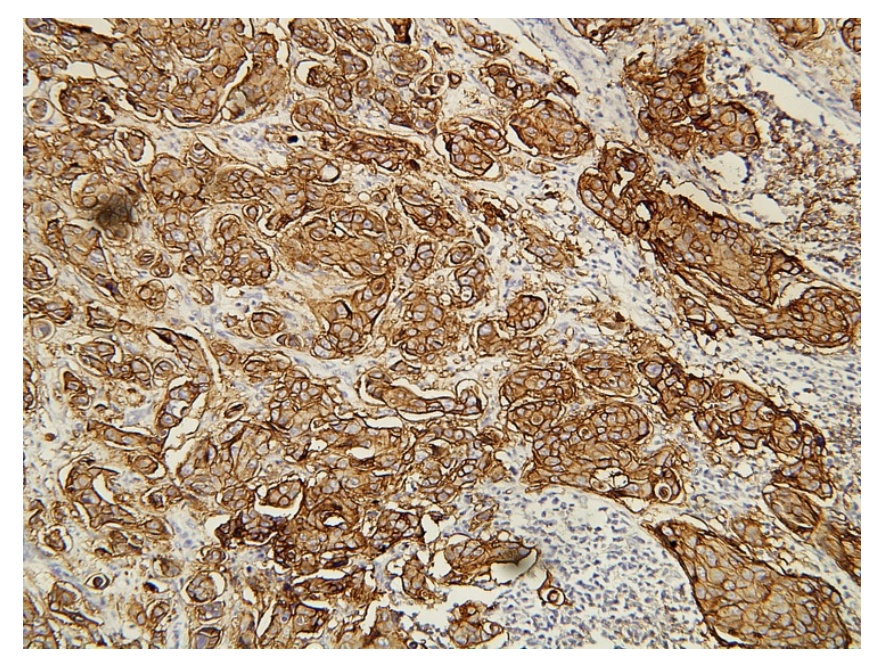

Figure 3

IHC stain of HER-2 oncoprotein. Showing positive expression of HER-2 oncoprotein on carcinoma cell membrane. $(S P \times 200)$. 


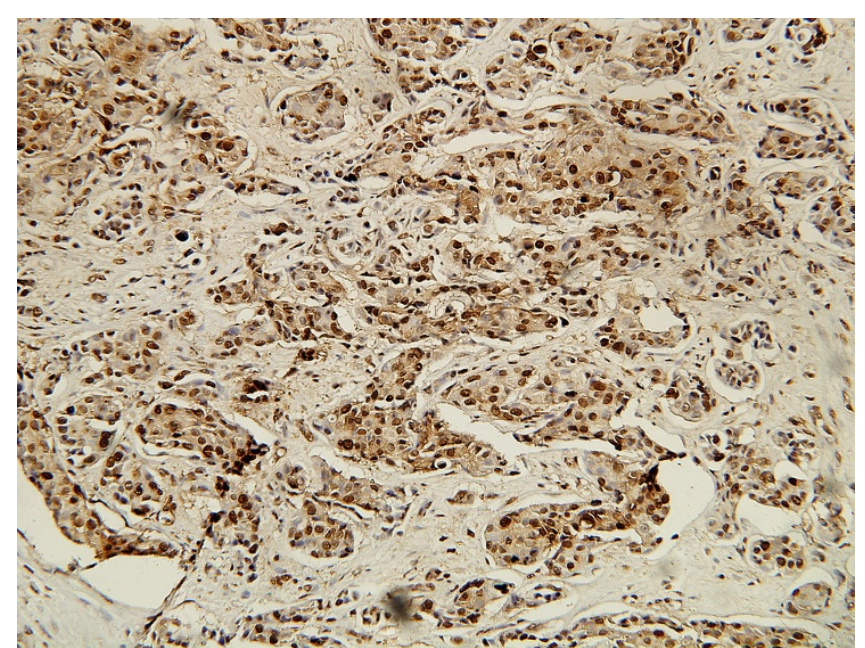

Figure 4

IHC stain of PCNA. Showing positive expression of PCNA in carcinoma cell nuclei. $(\mathrm{SP} \times 200)$.

Recently, the genetic factors got more attention by scientists $[4,5]$. The mutations of BRCA1, BRCA2 and MMR gene may play very important roles in the onset of the male breast cancer; and other genetic factors involved could include AR gene, CHEK2 gene, cytochrome P45017 (CYP17), the XXY karyotype (Klinefelter syndrome), and the PTEN tumor suppressor gene associated with Cowden syndrome, and so on. The BRCA1 and BRCA2 germ-line mutation is known associated with the hereditary breast cancer [6]; and the MMR germ-line mutation (especially $h M L H 1)$ for the hereditary nonpolyposis colorectal carcinoma (HNPCC). Some researchers regarded the breast

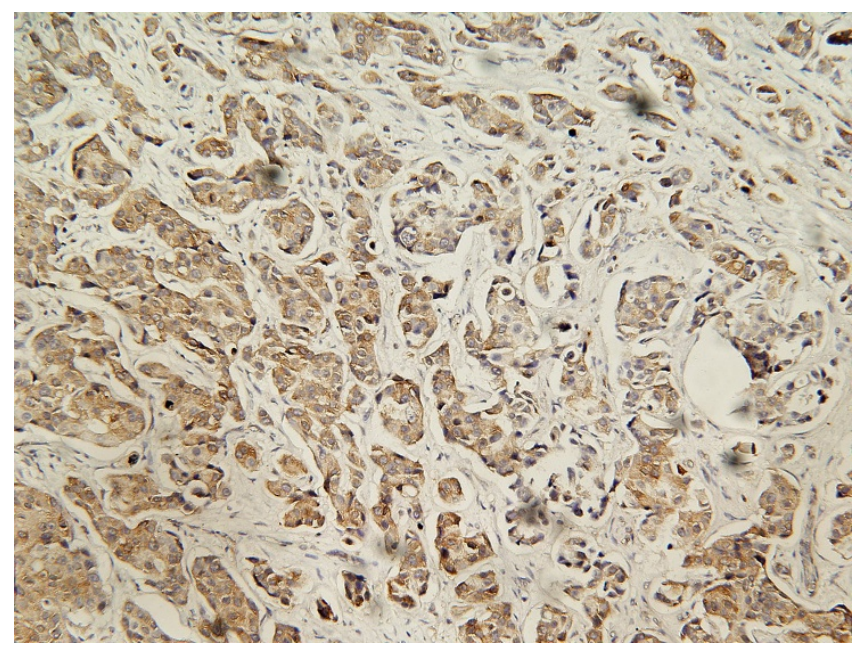

Figure 5

IHC stain of Bcl-2 oncoprotein. Showing positive expression of Bcl-2 oncoprotein in carcinoma cell cytoplasm. (SP $\times 200$ ).

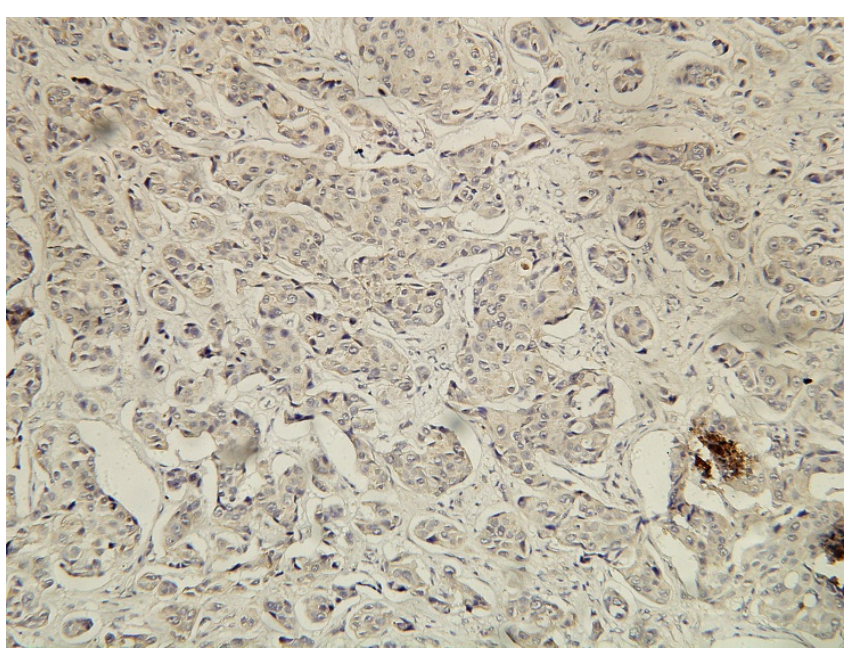

Figure 6

IHC stain of $\mathbf{n m} 23$ protein. Showing positive expression of $\mathrm{nm} 23$ protein in carcinoma cell cytoplasm. $(S P \times 200)$.

cancer, especially the male breast cancer, as a part of the tumor spectrum of HNPCC, and thought the breast cancer might be an extracolonic manifestation of HNPCC [7]. Therefore, if a male patient with breast cancer is met with in clinic, we should attend not only to examine the breast focus, but also to inquire the patient about his family history and post history which is helpful for clinical diagnosis and therapy.

Occult breast cancer is even rarer in men. It usually presents lymph node metastasis of axilla, supraclavicular fossa and infraclavicular fossa as the first manifestation [8]. In our case, the patient presented axillary lymph node

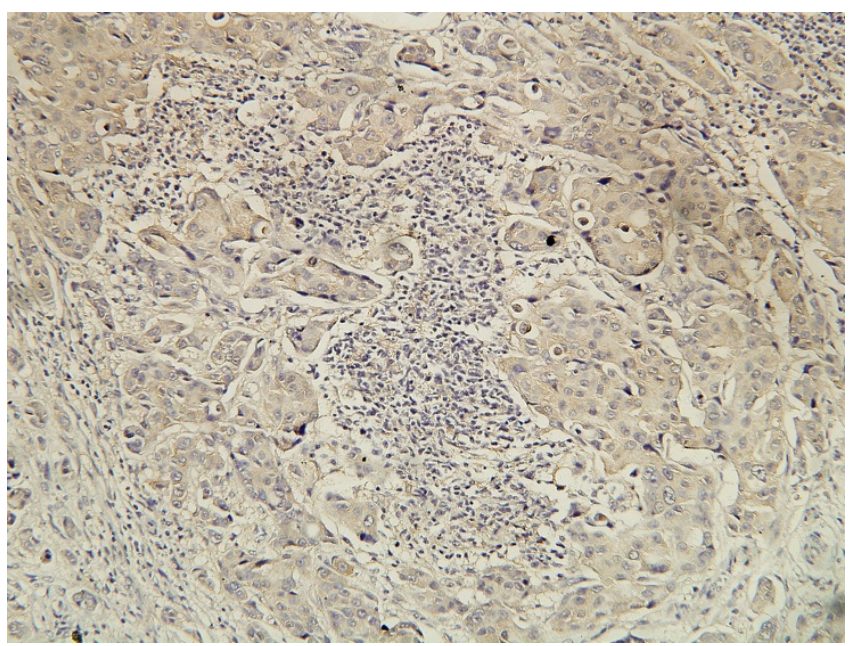

Figure 7

IHC stain of MRP. Showing positive expression of MRP in carcinoma cell cytoplasm. $(\mathrm{SP} \times 200)$. 


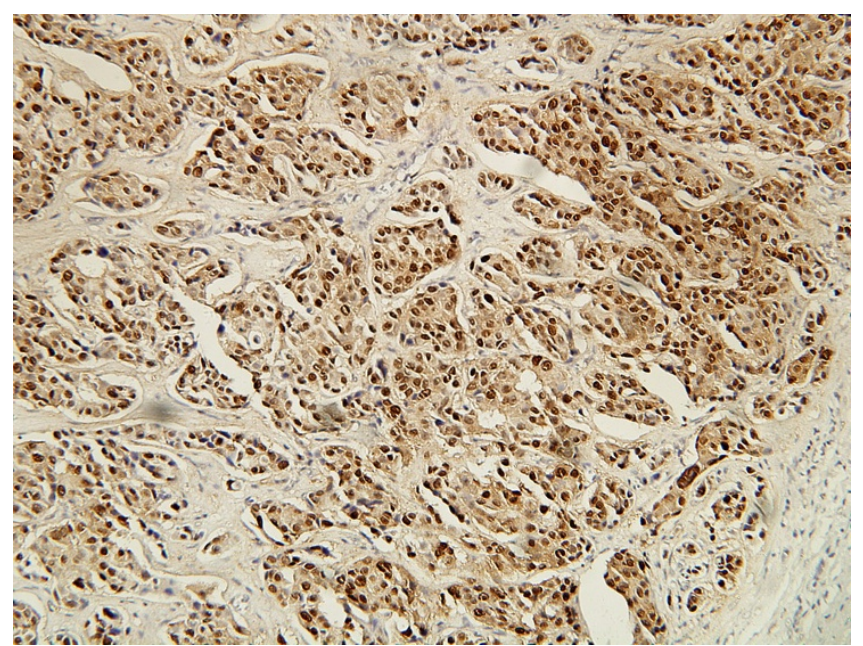

Figure 8

IHC stain of P53 protein. Showing positive expression of P53 protein in carcinoma cell nuclei. $(S P \times 200)$.

metastasis as the first manifestation. The most common causes of axillary malignant lymph nodes include lymphoma and metastasis from breast cancer, lung cancer, melanoma, and squamous cell cancer. So, we should give our attention to take relevant examination to find focus and avoid misdiagnosis, if we meet with similar patients in clinic. Research shows that it is in approximately $50 \%$ cases with occult breast cancer the cancer focus still can not be found in the breast specimen [9]. In our case, no tumor focus was found in breast specimen. The final diagnosis was made after many pathologists' consultation and a series of examinations for differential diagnosis. Hereby, the histological examination and IHC stain of metastasis focus is very important in the diagnosis of the occult breast cancer.

The currently recommended surgical therapy in clinic is the modified radical mastectomy with axillary dissection. It was reported that male breast carcinomas have a higher positive rate of hormone receptor than the female breast carcinomas, and so the adjuvant hormonal therapy is theoretically very promising [10]. In our case, although the tumor cells were negative for ER and $\mathrm{PR}$, the expression results of PCNA, P53, Bcl-2, nm23, MRP and HER-2 protein were similar to other reports [1-4]. Because he was a septuagenarian, his families did not agree with him to undergo endocrine-therapy, chemotherapy and radiotherapy after operation. But the patient's prognosis seems well; he has survived with cancer-free for about 29 months after diagnosed, and he is still in follow-up.

\section{Consent}

The consent was obtained from the patient for publication of this case report and accompanying images. We have obtained consent for publication in print and electronically from the patient.

\section{Competing interests}

The authors declare that they have no competing interests. We all authors have seen and approved the submitted version of this manuscript. There was not a medical writer or editor involved in the generation of our manuscript. We are assured that the manuscript has not been published or submitted for publication elsewhere except as a brief abstract in the proceedings of a scientific meeting or symposium.

\section{Authors' contributions}

Gu GL and Wang SL designed the research. Gu GL and Zou FX collected the clinical data and wrote the manuscript. Ren L collected the pathological data. Wang SL, Wei $\mathrm{XM}$ and Zou FX revised the manuscript.

\section{References}

I. Giordano $\mathrm{SH}$ : A review of the diagnosis and management of male breast cancer. Oncologist 2005, I 0(7):47I-479.

2. Giordano SH, Buzdar AU, Hortobagyi GN: Breast cancer in men. Ann Intern Med 2002, I37(8):678-687.

3. Namba N, Hiraki A, Tabata M, Kiura K, Ueoka H, Yoshino T, Tanimoto $M$ : Axillary metastasis as the first manifestation of occult breast cancer in a man: a case report. Anticancer Res 2002, 22(6B):36| I-36I3.

4. Weiss JR, Moysich KB, Swede H: Epidemiology of male breast cancer. Cancer Epidemiol Biomarkers Prev 2005, I 4(I):20-26.

5. Lynch HT, Watson P, Narod SA: The genetic epidemiology of male breast carcinoma. Cancer 1999, 86(5):744-746.

6. Palli D, Falchetti M, Masala G, Lupi R, Sera F, Saieva C, D'Amico C, Ceroti M, Rizzolo P, Caligo MA, Zanna I, Ottini L: Association between the BRCA2 N372H variant and male breast cancer risk: a population-based case-control study in Tuscany, Central Italy. BMC Cancer 2007, 7: I70.

7. Müller A, Edmonston TB, Corao DA, Rose DG, Palazzo JP, Becker H, Fry RD, Rueschoff J, Fishel R: Exclusion of breast cancer as an integral tumor of hereditary nonpolyposis colorectal cancer. Cancer Res 2002, 62(4): 1014-1019.

8. Burga AM, Fadare O, Lininger RA, Tavassoli FA: Invasive carcinomas of the male breast: a morphologic study of the distribution of histologic subtypes and metastatic patterns in $\mathbf{7 7 8}$ cases. Virchows Arch 2006, 449(5):507-5I 2.

9. Chen L, Chantra PK, Larsen LH, Barton P, Rohitopakarn M, Zhu EQ, Bassett LW: Imaging characteristics of malignant lesions of the male breast. Radiographics 2006, 26(4):993-1006.

10. Erhan $Y$, Zekioglu $O$, Erhan Y: Invasive lobular carcinoma of the male breast. Can J Surg 2006, 49(5):365-366.

Publish with Bio Med Central and every scientist can read your work free of charge

"BioMed Central will be the most significant development for disseminating the results of biomedical research in our lifetime. "

Sir Paul Nurse, Cancer Research UK

Your research papers will be:

- available free of charge to the entire biomedical community

- peer reviewed and published immediately upon acceptance

- cited in PubMed and archived on PubMed Central

- yours - you keep the copyright 